\title{
BUNGA SURIAN (Toona sinensis (A. Juss.) M. Roem.): MORFOLOGI, FENOLOGI, DAN SERANGGA PENGUNJUNG
}

\author{
(Surian (Toona sinensis (A. Juss.) M. Roem.) Flowers: Morphology, \\ Phenology, and Insects Visitors)
}

\author{
Agus Astho Pramono ${ }^{1}$, Endah R. Palupi ${ }^{2}$, Iskandar Z. Siregar ${ }^{3}$, dan/and Cecep Kusmana ${ }^{3}$ \\ ${ }^{1)}$ Balai Penelitian Teknologi Perbenihan Tanaman Hutan, Jl. Pakuan Ciheuleut PO. BOX 105, Telp/Fax: \\ 0251-8327768, Bogor, Indonesia \\ ${ }^{2)}$ Fakultas Agronomi Institut Pertanian Bogor, Kampus IPB Darmaga, Jl. Meranti, Babakan, Dramaga, \\ (0251) 8629353 Bogor, Indonesia \\ ${ }^{3)}$ Fakultas Kehutanan Institut Pertanian Bogor, Jl. Lingkar Akademik Kampus IPB, Dramaga, Babakan, \\ Dramaga Telp.(0251) 8621677, Bogor, Indonesia \\ e-mail: agusastho@gmail.com
}

Naskah masuk: 8 Desember 2016; Naskah direvisi: 9 Desember 2016; Naskah diterima: 14 Desember 2016

\begin{abstract}
Efforts to improve the productivity of a seed source require a deep understanding of reproductive characteristics and environmental factors that affect the seed production. This study aimed to investigate the characteristics of reproduction which include 1) the characteristics of flower morphology and phenology, and 2) the identification of flower visitors of surian. Studies conducted in the smallholder forest in Sumedang, West Java. Surian flowers were compound flower that arranged in panicles shape. When a flower blooms, petals do not open fully, formed like a tube. Male flowers are smaller than female flowers and never bloom, and the male flowers fall first. Branching patterns of surian flower panicle is thyrses, and flowers bloom not simultaneously. The development of flower from buds to bloom takes approximately 12 days, the flowers bloom 1-3 days, development of fruit until ripe takes 5-5.5 months. It is found 12 species of insects visiting flowers, 11 species are considered very small. Insects those are found in large quantities were Thrips and three species of Nitidulidae.
\end{abstract}

Keywords: flower, fruit, inflorescence, insect flower visitors, seed

\begin{abstract}
ABSTRAK
Upaya untuk meningkatkan produktifitas suatu sumber benih memerlukan suatu pemahaman yang mendalam tentang ciri reproduksi dan faktor-faktor lingkungan yang berpengaruh terhadap hasil benih. Penelitian ini bertujuan untuk (1) mengetahui ciri morfologi bunga dan fenologinya, dan 2) mengenali serangga pengunjung bunga surian. Kajian dilakukan di hutan rakyat di Kabupaten Sumedang Provinsi Jawa Barat. Bunga surian merupakan bunga majemuk yang tersusun dalam malai berbentuk panikel. Ketika bunga mekar mahkota bunga tidak terbuka sepenuhnya, membentuk mirip tabung. Bunga jantan berukuran lebih kecil dari bunga betina dan tidak pernah mekar, dan bunga jantan rontok lebih dahulu. Malai bunga surian memiliki pola percabangan thyrses, dan bunga mekar tidak serentak. Perkembangan bunga dari tunas yang berwarna hijau hingga bunga mekar memerlukan waktu sekitar 12 hari, bunga mekar bertahan 2 atau 3 hari, Perkembangan buah hingga buah masak dan terbuka memerlukan waktu $5-5.5$ bulan. Terdapat 12 jenis serangga yang mengunjungi bunga surian, 11 jenis berukuran sangat kecil. Serangga yang ditemukan dalam jumlah banyak adalah thrips dan 3 jenis serangga famili Nitidulidae.
\end{abstract}

Kata kunci: benih, bunga, bunga majemuk, penyerbuk, serangga pengunjung bunga 


\section{PENDAHULUAN}

Benih yang berkualitas dengan pasokan yang mencukupi merupakan salah satu syarat penting dalam pembangunan hutan. Hal ini perlu didukung oleh keberadaan sumber benih yang dikelola secara benar. Suatu pengelolaan yang mampu menghasilkan benih dengan kualitas genetik dan kuantitas yang tinggi memerlukan pemahaman yang mendalam tentang faktor-faktor yang mempengaruhi hasil benih. Pemahaman ini perlu diawali dengan mengenali ciri pembungaan dan penyerbukan dari jenis tanaman yang dikembangkan.

Bunga tanaman Angiospermae mempunyai sistem yang kompleks dan terpadu dengan bunga berfungsi untuk memastikan dan memaksimalkan reproduksi (Chouteau et al., 2006). Oleh karena itu, memahami ciri bunga merupakan suatu langkah penting dalam upaya memahami reproduksi suatu jenis tanaman. Potensi hasil benih tanaman sangat dipengaruhi oleh ciri biologi bunga yang berkaitan erat dengan tipe perkawinan dan kelamin. Bawa et al. (1989) menyatakan bahwa sekitar 60-65\% pohon di hutan hujan dataran rendah telah ditemukan bersifat hermafrodit, 11-14\%-nya adalah monocious dan 23-26\% dioecious.

Keluarga Toona memiliki bunga yang secara morfologi bertipe biseksual, dengan benang sari (stamen) atau putik (pistil) berkembang baik yang secara fungsional sebagai bunga jantan atau betina (Gouvea et al., 2008). Surian (Toona Sinensis) termasuk tanaman berumah satu (monoecious). Tanaman ini memiliki karakteristik bunga berumah satu sehingga bunganya berkembang secara dichogamy, polygamy atau anomali (Edmonds \& Staniforth, 1998). Musim berbunga dan berbuah surian berbeda antar pohon, sehingga pohon surian yang sedang berbunga dan berbuah hampir selalu dapat ditemukan sepanjang tahun pada tegakan yang memiliki populasi banyak (Pramono, 2013).

Aroma bunga surian yang kuat memberikan petunjuk bahwa penyerbuknya adalah serangga (Edmonds \& Staniforth, 1998). Dengan demikian mengenali serangga pengunjung bunga surian sangat diperlukan guna memahami ciri penyerbuk dan faktor-faktor lingkungan yang berpeluang mendukung atau menghambat perannya sebagai vektor penyerbukan. Efektifitas serangga pengunjung untuk menjadi serangga penyerbuk (pollinator) tergantung pada daya mengangkut serbuk sari (pollen load) dan kemampuan meletakkan serbuk sari pada kepala putik yang reseptif (Johnson \& Steiner, 2000; Lau \& Galloway, 2004). Jenis penyerbuk yang berbeda yang memiliki ciri berbeda, memerlukan lingkungan hidup yang berbeda. Tanaman yang penyerbukanya dibantu oleh hewan, untuk meningkatkan peluang terjadinya penyerbukan, memiliki bunga dengan bentuk tertentu sebagai penyesuaian terhadap penyerbuknya, dan menghasilkan imbalan yang dapat menarik penyerbuk. Perbedaan ciri-ciri bunga antar jenis dapat 
mempengaruhi tindakan penyerbuk sehingga berakibat pada perbedaan tingkat keberhasilan reproduksinya (Navarro et al., 2007).

Penelitian ini bertujuan untuk (1) mengetahui ciri morfologi bunga dan fenologinya dan 2) mengidentifikasi serangga pengunjung bunga surian.

\section{BAHAN DAN METODE}

\section{A. Lokasi dan waktu penelitian}

Kajian dilakukan di hutan rakyat di Kabupaten Sumedang Provinsi Jawa Barat. Kabupaten Sumedang terletak antara $6^{\circ} 44^{\prime}-$ $70^{\circ} 83^{\prime}$ LS dan $107^{\circ} 21^{\prime}-108^{\circ} 21^{\prime}$ BT. Wilayah di Kabupaten Sumedang memiliki tipe hujan yang menurut klasifikasi Schmidt dan Ferguson termasuk pada iklim agak basah dan sedang yaitu tipe $\mathrm{C}$ dan D. Penelitian ini dilakukan di Desa Padasari Kecamatan Cimalaka dan Desa Sukajadi Kecamatan Wado.

Kecamatan Wado memiliki curah hujan $5.182 \mathrm{~mm} \mathrm{th}^{-1}$, yang paling tinggi dibanding kecamatan-kecamatan lain di Kabupaten Sumedang, sedangkan curah hujan di Kecamatan Cimalaka yang sebesar $1.870 \mathrm{~mm}$ th ${ }^{1}$ (BPS Kabupaten Sumedang 2013). Sebagian besar $(59.81 \%)$ area di Kecamatan Wado memiliki jenis tanah Latosol, sisanya 19.62\% merupakan tanah Andosol, dan 20.57\% jenis tanah Mediteran. Di Kecamtan Cimalaka sebagian besar lahan (55.35\%) memiliki jenis tanah Regosol, 10.73\% berjenis tanah Aluvial, dan 33.91\% berjenis tanah Latosol.
Di Kecamatan Wado penelitian dilakukan di Desa Sukajadi. Lokasi penelitian berada di $108^{\circ} 06^{\prime} 02^{\prime \prime}-108^{\circ} 07^{\prime} 54^{\prime \prime B T, ~ d a n ~ 6 ~ 6 ~} 58^{\prime} 30^{\prime \prime}$ $7^{\circ} 00^{\prime} 44^{\prime \prime L S}$, pada ketinggian 660-860 m dpl dengan topografi bergelombang dan miring. Di Kecamatan Cimalaka, penelitian dilakukan di Desa Padasari. Lokasi berada di 10755'35"10756'26"BT dan 6²5'36"-6²6'37"LS pada ketinggian 685-700 $\mathrm{m}$ dpl, berada pada area yang datar. Lokasi penelitian di Sukajadi berada pada lahan hutan rakyat yang dikelilingi oleh perladangan lahan kering, sedangkan lokasi penelitian di Desa Padasari berada pada hutan rakyat yang secara umum dikelilingi oleh hutan pinus, sawah, dan pemukiman penduduk.

\section{B. Ciri Bunga dan Fenologinya}

Dalam penelitian ini, dilakukan pengamatan organ-organ reproduktif, dan struktur karangan bunga (malai). Pengamatan ukuran dan struktur bunga meliputi pengamatan ukuran dan jumlah kelopak (sepal), mahkota (petal), benang sari dan putik. Selain itu juga dipelajari struktur karangan bunga, serta letak bunga jantan dan betina di dalam malai. Jumlah total bunga surian pada setiap malai dihitung pada 99 malai dari 27 pohon contoh, pengamatan dilakukan dari 3 atau 4 malai dari setiap pohon contoh. Bunga pada 9 cabang contoh dari malai contoh diamati fenologinya, diawali dengan 90 butir tunas bunga berwarna hijau dan 83 bunga kecil berwarna putih. Pengamatan dilakukan 2 hari sekali hingga terbentuk buah kecil. Pengamatan fenologi dari 
buah kecil sampai menjadi buah masak dilakukan pada 30 pohon contoh.

Pengamatan dilakukan mulai dari Agustus 2011 sampai dengan Mei 2013. Karena musim buah tidak serentak antar pohon (Pramono 2013), maka pengambilan contoh dan pengamatan tidak dapat dilakukan secara serentak. Pengambilan contoh dilakukan pada bulan Agustus dan November 2011, kemudian sebulan sekali dari Maret sampai Juni tahun 2012. Pengambilan contoh juga dilakukan pada bulan November 2012 dan Mei 2013. Pengamatan jumlah bunga, jumlah benih, ukuran buah dan identifikasi serangga dilakukan di Laboratorium Balai Penelitian dan Pengembangan Teknologi Perbenihan Tanaman Hutan di Bogor. Contoh bunga dianalisis secara deskriptif.

\section{Serangga Pengunjung Bunga}

Pengamatan serangga pengunjung bunga dilakukan pada contoh karangan bunga yang diambil dari 3 pohon di Desa Padasari, dan 4 pohon di Desa Sukajadi Kecamatan Cimalaka Kabupaten Sumedang. Pada setiap pohon diambil 2 atau 3 malai, tergantung ketersediaan malai yang dapat digunakan untuk contoh. Serangga pengunjung bunga dikumpulkan dengan cara membungkus karangan bunga yang masih berada di pohon dengan plastik yang berukuran besar secara perlahan-lahan agar serangga yang ada pada bunga tidak terusik. Setelah semua bunga masuk ke dalam plastik, tangkai bunga dipotong dan plastik ditutup. Kemudian jenis-jenis serangga yang terperangkap di dalam plastik diambil, dimasukkan ke dalam botol berisi alkohol. Di laboratorium, semua jenis serangga yang tertangkap dikenali menggunakan buku $A n$ Introduction to the Study of Insect (Borror et al. 1992) dan website BugGuide.Net (http://bugguide.net/node/view/15740).

\section{Analisis Data}

Analisis data dilakukan secara deskriptif. Data tentang karakteristik bunga, perkembangan bunga dan serangga pengunjung bunga ditampilkan dan dibahasa secara kualitatif berdasarka penampakan visual yang meliputi ukuran (mm), waktu (hari), warna, dan bentuk (foto atau ilustrasi).

\section{HASIL DAN PEMBAHASAN}

\section{A. Hasil}

\section{Struktur Bunga dan Karangan Bunga}

Bunga surian merupakan bunga majemuk yang tersusun dalam malai berbentuk panikel (Gambar 1a). Sebagian besar bunga surian yang ditemui di Desa Sukajadi dan Padasari berwarna putih, pada individu-individu tertentu ditemukan bunga berwarna putih kemerahan pada ujung mahkota bunga. Surian memiliki bunga yang secara morfologis biseksual karena pada setiap bunga terdapat organ kelamin jantan maupun betina, tetapi secara fungsional berkelamin tunggal, dengan benang sari berkembang baik pada bunga jantan dan putik berkembang baik pada bunga betina. Bunga jantan dan betina berada pada satu malai (Gambar 1b, 1c, 1d). Bunga jantan dan betina memiliki organ lengkap. 

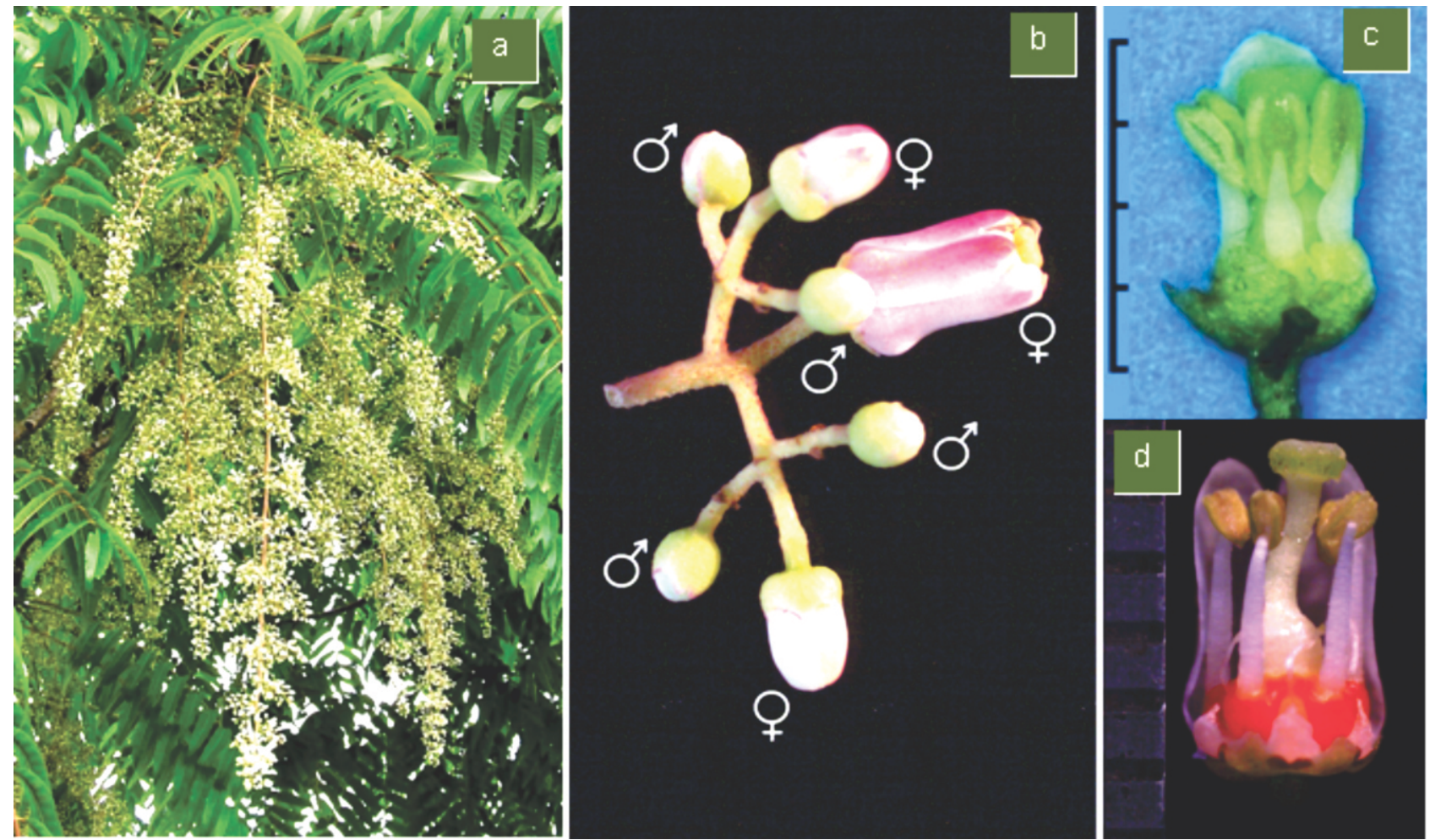

Gambar(Figure) 1. Bunga surian: a) malai bunga surian, b) letak bunga jantan dan betina, c) bunga jantan, d) bunga betina. (Surian flowers: a) flower panicle, b) the arrangement of male and female flowers, c) maleflowers, d) female flowers).

Ketika bunga mekar mahkota bunga tidak terbuka sepenuhnya, membentuk seperti tabung. Kepala putik pada bunga betina yang mekar seringkali lebih tinggi dari mahkota bunga atau sedikit menonjol keluar dari mahkota bunga. Bunga memiliki 5 mahkota bunga yang bersambungan, 5 mahkota bunga memiliki bentuk dan ukuran sama, 5 tangkai sari dan 1 tangkai putik. Panjang mahkota bunga adalah 3.6-4.5 mm, lebarnya $1.8-2.3 \mathrm{~mm}$, panjang tangkai putik(stylus) 3.2-4.1 mm, lebar kepala putik (stigma) $1.0-1.3 \mathrm{~mm}$, panjang tangkai sari (filament) $2.5-3.5 \mathrm{~mm}$, lebar kepala sari (anther) 0.8-0.9 mm. Bunga jantan berukuran lebih kecil dari bunga betina. Tidak ditemukan bunga jantan yang mahkotanya mekar sepenuhnya, mahkota bunga jantan hanya sedikit terbuka di ujungnya, bunga jantan rontok lebih dahulu. Panjang mahkota bunga jantan 2.4-2.8 mm, lebar 1.3-1.8 mm, panjang tangkai putik $1.65-1.8 \mathrm{~mm}$. Kepala putik pada bunga jantan memiliki lebar 0.8-1.0 $\mathrm{mm}$ dan tidak tampak dari luar, tangkai sari bunga jantan berukuran 9.0-1.2 mm, kepala sari memiliki lebar $0.72-0.75 \mathrm{~mm}$.

\section{Pola percabangan malai bunga}

Panjang malai bunga surian bisa mencapai $1 \mathrm{~m}$. Malai bunga surian memiliki pola percabangan thyrses, bercabang-cabang secara bertingkat, sehingga pada malai surian dapat ditemui cabang tingkat pertama (primer), kedua 
(sekunder), ketiga (tersier), sampai keempat (quarterner) (Gambar 2). Panjang cabang primer pertama yang paling dekat dengan pangkal malai dapat mencapai $70 \mathrm{~cm}$. Setiap cabang malai biasanya berujung dengan 3 bunga (cyme). Bunga jantan dan betina pada malai tidak tersebar secara acak. Pada setiap cyme 1 bunga betina berada di tengah, dan diapit oleh dua bunga jantan yang berada di lateral. Bunga di dalam satu malai mekarnya tidak serentak. Bunga yang berada pada ujung cabang cenderung mekar terlambat, sehingga ketika berada di pohon bunga yang berada di bagian atas (pangkal cabang) lebih dahulu mekar daripada bunga yang berada di bagian bawah (ujung cabang).

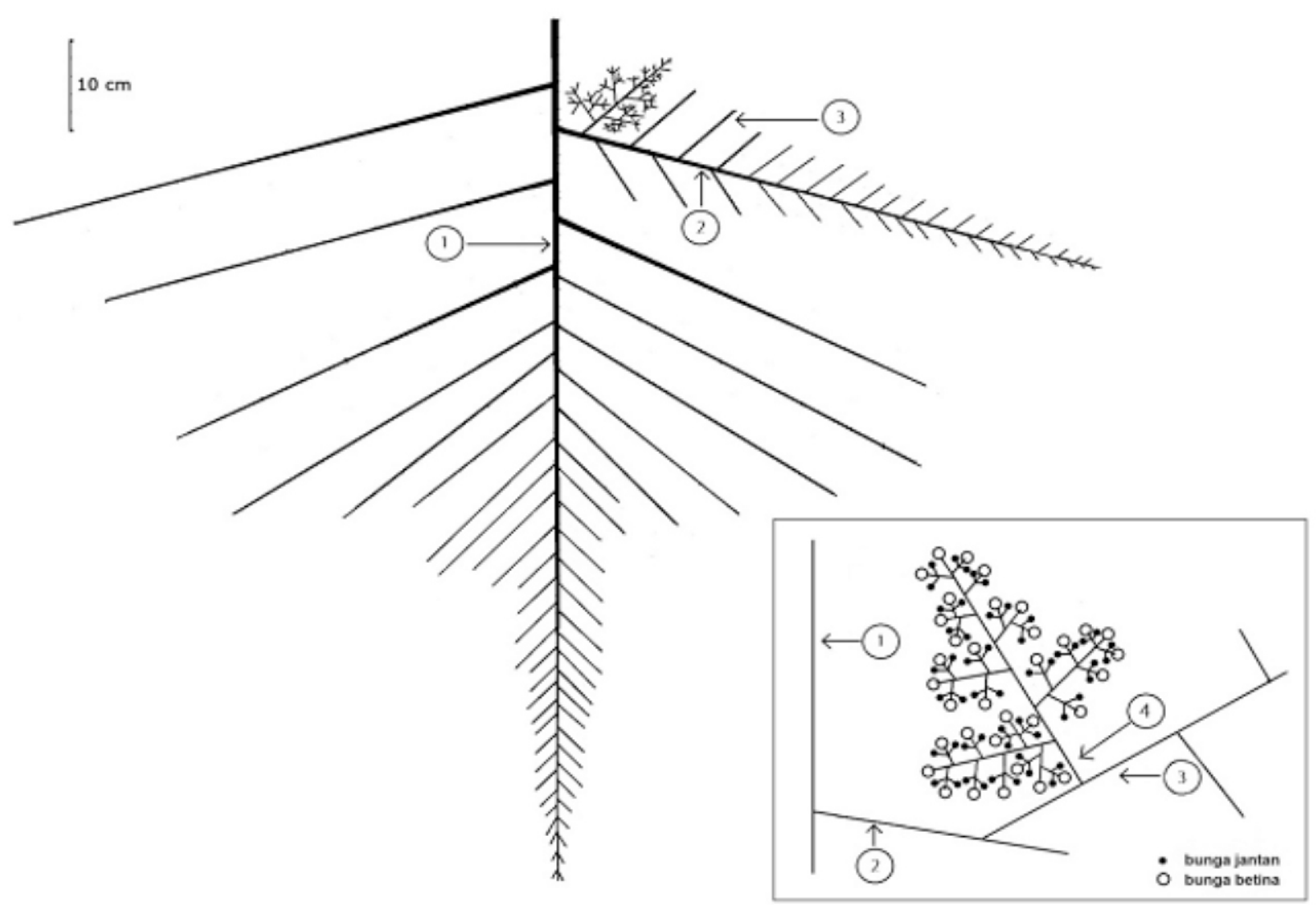

Gambar(Figure) 2. Sketsa susunan malai bunga surian: 1) tangkai utama, 2) cabang primer, 3) cabang sekunder, 4) cabang tersier. (The Sketch of flower panicles arrangement: 1) the main stalk, 2) primary branches, 3) secondary branches, 4) tertiary branches). 
BUNGA SURIAN (Toona sinensis (A. Juss.) M. Roem.): MORFOLOGI, FENOLOGI, DAN SERANGGA PENGUNJUNG

\section{Fenologi bunga dan buah}

Perkembangan bunga dari tunas yang berwarna hijau hingga bunga mekar memerlukan waktu sekitar 12 hari. Setelah mekar bunga bertahan 2 atau 3 hari, kemudian mahkota bunga layu, gugur dan buah kecil terbentuk dalam waktu 1 minggu. Perkembangan buah hingga buah masak dan terbuka memerlukan waktu 5 sampai 5.5 bulan (Gambar 3).

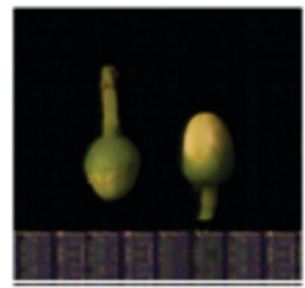

tuna bunge, bulat kedl, hijau (flower buds, small gboubr, green)

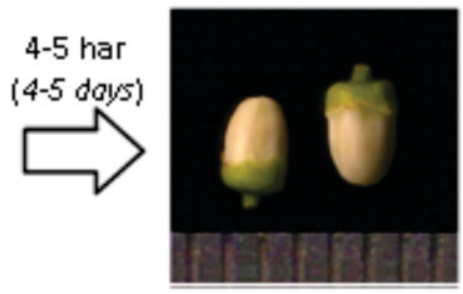

bungs bulat kedl, putih (mallflower, white)

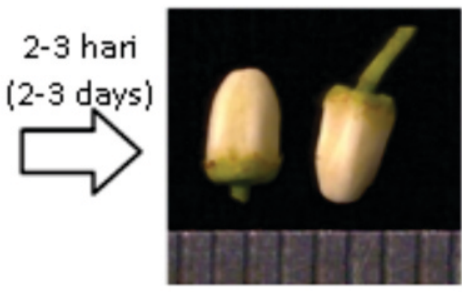

bunga memanjang putih (elongated flower, white)
4 hari

(4 days)
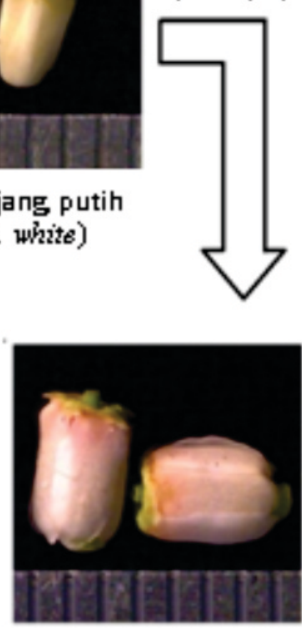

bunge mekar Dowers bloom)

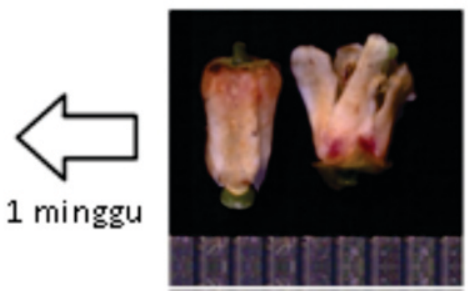

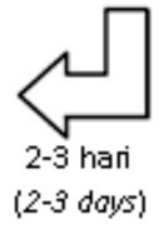

Bungalayu

(fiowers wi't) buah muda, hijau (young frit, green) buah terbentuk, kedil (fruit is formed, small)
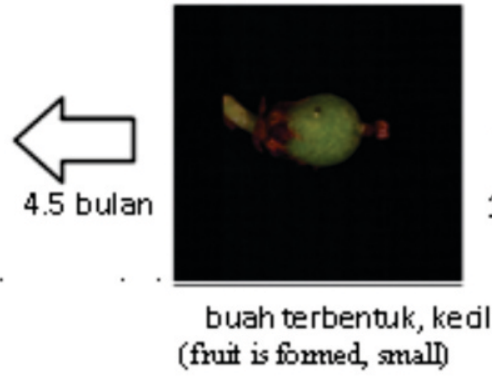

Gambar(Figure) 3. Tahap perkembangan bunga betina dan buah surian (Development stages of female flowers and fruit surian). 


\section{Serangga Pengunjung Bunga}

Dari hasil pengamatan ditemukan 12 jenis serangga pengunjung bunga surian (Gambar 4). Serangga yang tertangkap terdiri dari 6 jenis ( 5 famili) dari ordo Coleoptera, 1 jenis dari ordo Hemiptera, 1 jenis dari ordo Thysanoptera, dan 3 jenis dari ordo Diptera. Sebagian besar serangga pengunjung bunga surian yang tertangkap berukuran sangat kecil. Sepuluh jenis serangga berukuran lebih kecil dari ukuran bunga surian yaitu kurang dari $0.9 \mathrm{~mm}$ sampai $3.6 \mathrm{~mm}$, dan satu jenis berukuran lebih besar dari bunga yaitu famili Bibionidae yang berukuran $11.0 \mathrm{~mm}$.

Pada penelitian ini tidak dilakukan penghitungan jumlah individu dari setiap spesies yang ditemui, namun berdasarkan pengamatan kasar serangga yang ditemukan dalam jumlah banyak adalah thrips dari famili Thripidae dan jenis dari famili Nitidulidae sp 3, yang rata-rata berukuran kurang dari $2 \mathrm{~mm}$ (Tabel 1). Jenis thrips yang berada pada bunga surian dijumpai pada fase larva yang berwarna kekuning-kuningan pucat hampir tembus pandang tanpa sayap dengan kepala kecil, dan fase dewasa yang berwarna gelap dan memiliki sayap. Beberapa jenis dikenali sebagai famili Nitidulidae yang memiliki ciri antena 11 ruas, 3 ruas bergada yang bertipe kepala (kapitat) (Borror et al., 1992).

Serangga pengunjung bunga surian pada umumnya berada di dalam bunga sehingga tidak tampak melalui pengamatan dari luar. Serangga hanya tampak dari luar ketika berpindah dari bunga satu ke bunga lainnya.

Tabel (Table) 1. Ukuran dari jenis-jenis serangga yang tertangkap sebagai pengunjung bunga surian (Sizes of insects species trapped as flower visitors of surian).

\begin{tabular}{rlllc}
\hline No & $\begin{array}{c}\text { Ordo } \\
(\text { Order })\end{array}$ & $\begin{array}{l}\text { Famili } \\
(\text { Family })\end{array}$ & $\begin{array}{c}\text { Nama Inggris } \\
(\text { English name })\end{array}$ & $\begin{array}{c}\text { Ukuran }(\mathrm{mm}) \\
(\text { Size })\end{array}$ \\
\hline 1 & Coleoptera & Nitidulidae & - & 2.5 \\
2. & Coleoptera & Nitidulidae & Pollen beetles & 1.8 \\
3. & Coleoptera & Nitidulidae & Sap-feeding beetles & 1.9 \\
4 & Coleoptera & Pealacridae & Shining flower beetle & 1.9 \\
5 & Coleoptera & Curculionidae & Snout and bark beetles & 1.8 \\
6 & Coleoptera & Staphylinidae & Rove beetles & 1,5 \\
7 & Coleoptera & Anthicidae & Antlike flower beetles & 2.3 \\
8 & Hemiptera & Miridae & Plant bugs & 3.6 \\
9 & Thysanoptera & Thripidae & Thrips & 1.9 \\
10 & Diptera & Bibionidae & - & 11.0 \\
11 & Diptera & - & - & 2.5 \\
12 & Diptera & - & Flies & 0.9 \\
\hline
\end{tabular}




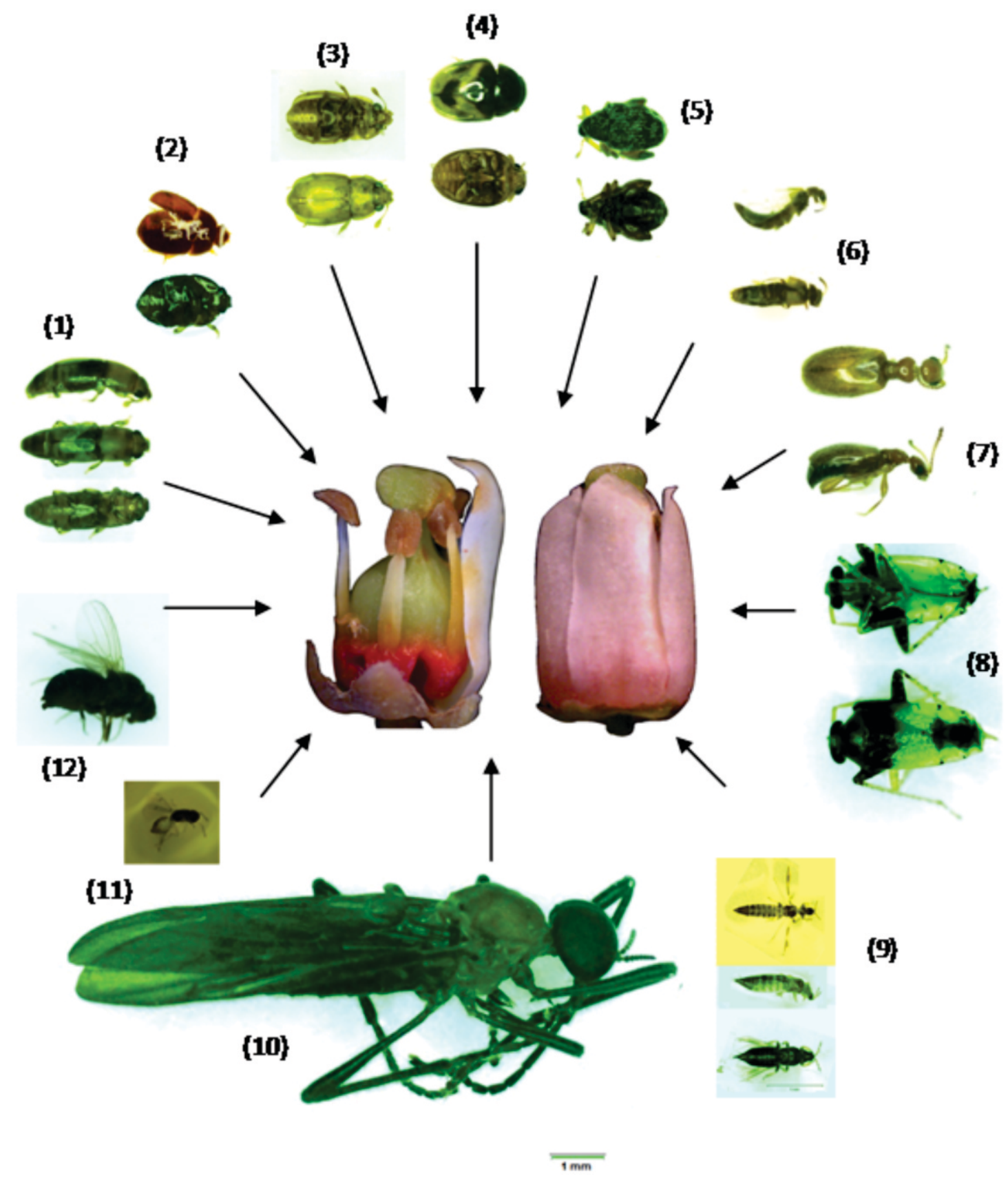

Gambar(Figure) 4. Serangga pengunjung bunga Surian. Ordo Coleoptera, famili Nitidulidae spesies 1 (1), famili Nitidulidae, spesies 2 (2), famili Nitidulidae, spesies 3 (3), famili Phalacridae (4), famili Curculionidae (5), famili Staphylinoidae (6), famili Anthicidae (7) ordo Hemiptera famili Miridae (8), ordo Thysanoptera famili Pheleothripidae (9), ordo Diptera famili Bibionidae (10), ordo Diptera (11), dan ordo Diptera (12). (Insect flower visitors of surian. Order Coleoptera, family Nitidulidae species 1 (1), the family Nitidulidae, species 2 (2), the family Nitidulidae, species 3 (3), the family Phalacridae (4), the family Curculionidae (5), the family Staphylinoidae (6), the family Anthicidae (7) the order Hemiptera, family Miridae (8), the order Thysanoptera, family Pheleothripidae (9), the order Diptera, family Bibionidae (10), the order Diptera (11), and the order Diptera (12)) 


\section{B. Pembahasan}

Selama pengamatan, bunga jantan selalu ditemukan dalam keadaan tertutup tidak ditemukan bunga jantan yang mekar. Hal ini memberi petunjuk bahwa penyerbuk efektif dari bunga surian adalah serangga yang ukurannya lebih kecil dari bunga jantan karena untuk mengangkut serbuk sari (pollen) serangga harus menyentuh kepala sari dengan cara masuk ke dalam rongga bunga jantan. Bunga betina ketika mekar tidak terbuka lebar namun menyerupai tabung dengan ujung sedikit terbuka. Kepala putik sering tampak sedikit menonjol melebihi mahkota bunga. Dengan demikian penyerbuk yang telah membawa serbuk sari tidak harus masuk ke dalam bunga betina untuk membantu penyerbukan.

Bunga surian mekar hanya bertahan sekitar 2-3 hari. Hal ini menunjukkan bahwa peluang bunga untuk dapat terserbuki relatif singkat, sehingga ketika bunga mekar pada musim hujan maka intensitas hujan dan jumlah hari hujan yang mempengaruhi pergerakan penyerbuk diduga akan berpengaruh terhadap keberhasilan reproduksi surian, sebagaimana yang terjadi pada bunga kopi (Klein et al., 2003).

Hasil pengamatan menunjukkan bahwa serangga pengunjung bunga yang paling banyak ditemukan berdasarkan Lewis (1973) dan Borror et al. (1992) adalah jenis thrips. Secara umum, thrips termasuk serangga bersayap terkecil, memiliki ukuran sekitar 0.5-14 mm (Lewis, 1973). Jenis thrips yang dijumpai pada bunga surian yang berukuran sekitar $1.9 \mathrm{~mm}$.
Di dalam bunga surian, thrips ditemukan dalam bentuk larva maupun dewasa. Hal ini sesuai dengan hasil pengamatan Lewis (1973) yang menyatakan bahwa thrips tinggal di dalam bunga untuk mencari makan, kawin, meletakkan telur, dan membesarkan larva.

Makanan thrips di dalam bunga adalah nektar (Moog et al., 2002), atau serbuk sari (Hulshof \& Vänninen, 2001). Beberapa penelitian mengungkapkan bahwa thrips merupakan serangga yang berperan sebagai penyerbuk pada berbagai jenis tanaman (Lewis, 1973). Trips merupakan penyerbuk Manilkara zapota (Reddi, 1989), Xylopia aromatica (Jurgens et al., 2000), Macaranga hullettii (Moog et al., 2002), Shorea xanthophylla (Kettle et al., 2011), Ocotea porosa (DanieliSilva \& Varassin, 2013), juga merupakan penyerbuk untuk 13 tanaman hutan dataran rendah di New Zealand (Norton, 1984). Norton (1984) dan Moog et al. (2002) menyatakan bahwa thrips adalah vektor penyerbukan yang efektif. Garcia-Fayos and Goldarazena (2008) membuktikan bahwa karangan bunga Arctostaphyllos uvaursi yang hanya dikunjungi thrips dapat menghasilkan buah hampir 1/3-nya, sedangkan Moog et al. (2002) menemukan adanya serbuk sari yang menempel pada tubuh thrip. Terry (2001) mengungkapkan bahwa setiap individu thrips rata-rata dapat mengangkut 20 butir serbuk sari Macrozamia macdonnellii, atau 42 butir serbuk sari Macrozamia communis. (Terry, 2001). Kettle et al. (2011) menyatakan bahwa thrips berperan 
penting sebagai penyerbuk pada bunga yang berukuran kecil (2-4 mm), dan peranannya berkurang pada bunga yang berukuran lebih besar. Peran thrips dalam penyerbukan bunga surian perlu dikaji lebih lanjut, terutama terkait dengan efektivitasnya dalam membantu terjadinya penyerbukan silang.

Walaupun thrips berukuran kecil sehingga individu thrips hanya dapat mengangkut sedikit serbuk sari, namun thrips ditemukan dalam jumlah sangat banyak pada karangan bunga surian. Hal ini sesuai dengan hasil penelitian Moog et al. (2002), Lewis (1973) dan Kettle (2011) bahwa karena ukuran thrips yang kecil maka perannya sebagai penyerbuk Macaranga hullettii diimbangi dengan jumah individunya yang sangat banyak.

Jenis thrips yang dikenal sebagai penyerbuk efektif pada tanaman yang memiliki bunga berukuran kecil, pada bunga surian ditemukan dalam jumlah banyak sehingga serangga ini berpotensi sebagai penyerbuk bagi surian, namun penelitian ini belum dapat mengungkap peran serangga ini sebagai penyerbuk yang efektif bagi surian. Untuk memastikan peran thrips sebagai penyerbuk surian diperlukan penelitian lebih lanjut.

Dalam penelitian ini ditemukan beberapa kumbang (beetles, ordo Coleoptera) yang mengunjungi bunga surian. Beberapa laporan menyatakan bahwa jenis-jenis serangga yang termasuk dalam kelompok kumbang berperan sebagai penyerbuk. Serangga-serangga ini mengangkut dan menyebarkan serbuk sari ketika mengunjungi bunga untuk memakan serbuk sari (Obute, 2010). Jenis kumbang yang banyak ditemukan di bunga surian adalah famili Nitidulidae. Beberapa penelitian menunjukkan bahwa jenis-jenis dari famili Nitidulidae berperan sebagai penyerbuk (Crowson, 1988; Corlett, 2004, Proches \& Johnson 2009). Salah satu fase dalam siklus hidup serangga Nitidulidae berada di dalam tanah sehingga kondisi ekologis sekitar permukaan tanah berperan penting terhadap populasi serangga ini (Cline, 2005, Meikle \& Diaz, 2012, Ellis et al., 2004).

Jenis kumbang yang ditemukan namun jarang adalah famili Curculionidae dan Staphylinidae. Famili Staphylinidae antara lain merupakan penyerbuk pada tanaman Anonaceae (Jurgens et al., 2000) dan Stangeria eriopus (Proches \& Johnson, 2009). Jenis lain yang juga ditemukan dalam jumlah sedikit adalah famili Miride (ordo Hemiptera), 2 jenis dari ordo Diptera yaitu 1 jenis dari famili Bibionidae (ordo Diptera) yang berukurun relatif besar, dan 1 jenis tawon (wasp) yang berukuran kecil, serta 1 jenis lalat kecil dari ordo Hymenoptera. Jenis dari famili Miridae merupakan serangga yang dijumpai sebagai pengunjung bunga untuk mencari nektar (Collevatti et al., 1998, Jesse et al., 2006).

Surian yang memiliki bunga kecil menghasilkan bunga dalam jumlah banyak. Hal ini mendukung pernyataan Kettle et al. (2011) bahwa di hutan tropis tanaman yang memiliki bunga yang berukuran kecil menghasilkan 
bunga dalam jumlah banyak sebagai cara menarik penyerbuk. Menurut Kettle et al. (2011) akibat dari tanaman yang memiliki bunga berukuran kecil adalah penyerbuknya berukuran kecil, dan tingkat keberhasilan penyerbukannya lebih rendah dari pada tanaman berbunga besar. Serangga penyerbuk yang berukuran kecil, misalnya thrips memiliki jarak terbang yang dekat. Thrips bisa terbang dalam jarak yang jauh jika terbantu oleh angin. Dengan demikian, surian yang memiliki serangga penyerbuk yang berukuran kecil membutuhkan jarak tanam antar pohon yang dekat untuk meningkatkan hasil buah (Danieli-Silva and Varassin 2013). Selain itu berkaitan dengan ukuran serangga yang kecil maka pola penggunaan lahan dalam sumber benih surian diduga berpengaruh terhadap efektifitas penyerbukan sebagaimana penelitian Benjamin et al. (2014) yang menyatakan bahwa ukuran penyerbuk berpengaruh terhadap tanggapan penyerbuk tertahap perbedaan penggunaan lahan. Selain itu, karena pada salah satu tahapan rantai hidupnya, Thrips dan serangga Nitidulidae hidup di dalam tanah (Cline, 2005; Meikle \& Diaz, 2012; Ellis et al., 2004), kondisi ekologis sekitar permukaan tanah, yang dipengaruhi oleh pola penggunaan lahan, berperan penting terhadap populasi serangga ini.

\section{KESIMPULAN}

Dari hasil penelitian ini dapat disimpulkan bunga jantan surian berukuran lebih kecil dan berbentuk mirip tabung tertutup, dan tidak ditemukan bunga jantan yang mahkotanya terbuka. Bunga betina ketika mekar tidak terbuka sepenuhnya, dengan kepala putik sedikit menonjol melebihi mahkota bunga. Malai bunga surian memiliki pola percabangan thyrses, bercabang-cabang secara bertingkat. Bunga di dalam malai mekar tidak serentak. Bunga yang berada pada bagian atas (pangkal cabang) lebih dahulu mekar daripada bunga yang berada di bagian bawah (ujung cabang). Terdapat 12 jenis serangga yang mengunjungi bunga surian, 11 jenis berukuran sangat kecil yaitu panjang dari ujung perut hingga kepala kurang dari $3.6 \mathrm{~mm}$, dan dijumpai 1 jenis serangga yang berukuran $11.0 \mathrm{~mm}$. Thrips dan 3 jenis serangga famili Nitidulidae ditemukan dalam jumlah banyak di dalam bunga surian.

\section{UCAPAN TERIMA KASIH}

Ucapan terima kasih disampaikan kepada Bapak Bambang dan Bapak Yana Sudaryana (karyawan Unit Pelaksana Teknis Daerah (UPTD) Kehutanan di Wado), Bapak Entis (Ketua Kelompok Tani di Desa Padasari) serta Bapak Hasan Royani (teknisi di Balai Penelitian dan Pengembangan Teknologi Perbenihan Tanaman Hutan) atas bantuan teknis selama pengamatan di lapangan. Terima kasih juga disampaikan kepada Bapak Herman Suherman dan teknisi di Laboratorium Balai Penelitian dan Pengembangan Teknologi Perbenihan Tanaman Hutan untuk bantuannya selama pengamatan di Laboratorium. 


\section{DAFTAR PUSTAKA}

Bawa, K.S., Asthon, P.S., Primack, R.B., Terbocrgh, J., Nor, S.M., Ng, F.S.P., Hadley, M. (1989). Reproductive Ecology of Tropical Forest Plant. Research Insights and Management Implications. Special Issue-21 Biology International. The International Union of Biologocal Sciences.

Benjamin F.E.; Reilly J.R. and Winfree R. (2014). Pollinator body size mediates the scale at which land use drivers crop pollination services. Journal of Applied Ecology. 51:440-449.

Borror, D.J., Triplehorn, C.A., Johnson, N.F. (1992). Pengenalan Pelajaran Serangga. Partosoedjono S, penerjemah; Brotowidjoyo MD, editor. Yogyakarta. Gadjah Mada University Press. Terjemahan dari: An Intoduction to the Sudy of Insect.

BPS Kabupaten Sumedang. (2013). Kabupaten Sumedang dalam Angka Tahun 2012. Sumedang. Badan Pusat Statistik Sumedang.

Chouteau, M., Barabe, E., Gibernau, M. (2006). A comparative study of inflorescence characters and pollen-ovule ratios among the genera Philodendron and Anthurium (Araceae). Int. J. Plant Sci. 167(4):817-829).

Cline, A.R. (2005). Revision of Pocadius erichson (Coleoptera: Nitidulidae). Dissertation. The Department of Entomology. Louisiana State University and Agricultural and Mechanical College.

Corlett, C.T. (2004). Flower visitors and pollination in the Oriental (Indomalayan) Region. Biol. Rev. 79: 497-532.

Collevatti, R.G., Campos, L.A.O., Da Silva, A.F. (1998). Pollination ecology of the tropical weed Triumfetta semitriloba Jacq. (Tiliaceae), in the South-Eastern Brazil Rev. Brasil. Biol. 58(3): 383-392.

Crowson, R.A. (1988). Meligethinae as Possible Pollinators (Coleoptera: Nitidulidae). Entomol. Gener. 14(1): 06 1-062.

Danieli-Silva, A., Varassin, I.G. (2013). Breeding system and thrips (Thysanoptera) pollination in the endangered tree Ocotea porosa (Lauraceae): implications for conservation. Plant Species Biology 28: 31-40psbi_35431..40.

Edmonds, J.M., Staniforth, M. (1998). 348. Toona sinensis (Meliaceae). Curtis' Botanical Magazine. 15(3):186-193.
Ellis Jr, J.D., Hepburn, R., Luckman, B., Elzen, P.J. (2004). Effects of Soil Type, Moisture, and Density on Pupation Success of Aethina tumida (Coleoptera: Nitidulidae). Environmental Entomology. 33(4):794-798.

Garcia-Fayos, P.G., Goldarazena, A. (2008). The role of thrips in pollination of Arctostaphyllos uva-ursi. Int. J. Plant Sci. 169(6):776-781.

Gouvea, C.D.F., Dornelas, M.C., Rodriguez, A.P.M. (2008). Floral Development in the Tribe Cedreleae (Meliaceae, Sub-family Swietenioideae): Cedrela and Toona. Annals of Botany. 101:39-48.

Hulshof, J., Vänninen, I. (2001).Western flower thrips feeding on pollen, and its implications for control. Di dalam: Marullo R, Mound L, editor.Thrips and Tospoviruses: Proceedings of the 7th International Symposium on Thysanoptera. Reggio Calabria, Italy, from the $2^{\text {nd }}$ to the $7^{\text {th }}$ of July 200. Canberra: Australian National Insect Collection CSIRO. hlm 173179.

Jesse, L.C., Moloney, K.A., Obrycki, K.K. (2006). Insect pollinators of the invasive plant, Rosa multiflora (Rosaceae), in Iowa, USA. Weed Biology and Management. 6:235-240.

Johnson, S.D., and Steiner, K.E. (2000). Generalization versus specialization in plant pollination systems. Tree. 15(4):140-143.

Jurgens, A., Webber, A.C., Gottsberger, G. (2000). Floral scent compounds of Amazonian Annonaceae species pollinated by small beetles and thrips. Phytochemistry. 55: 551-558.

Kettle, C.J., Maycock, C.R., Ghazoul, J., Hollingsworth, P.M., Khoo, E. (2011) Ecological implications of a flower size/ number trade-off in tropical forest trees. PLoS ONE 6(2): e16111. doi:10.1371/journal.pone. 0016111. [20 Desember 2013].

Klein, A.M.; Dewenter, I.S.; and Tscharntke, T. (2003) Bee pollination and Fruit set of Coffea arabica and $C$. canephora (Rubiaceae). American Journal of Botany 90(1): 153-157.

Kuiper, S., Sklar, J. (2013) Practicing Statistics: Guided Investigations For The Second Course. Boston. Pearson.

Lewis, T. (1973) Thrips Their Biology, Ecology and Economic Importance. London. Academic Press. 
Meikle, W.G., Diaz, R. (2012) Factors affecting pupation success of the small hive beetle, Aethina tumida. Journal of Insect Science $12: 118$. Ava i lab e on 1 in e : http://www.insectscience.org/12.118.

Moog, U., Fiala, B., Federle, W., Maschwitz, U. (2002) Thrips pollination of the dioecious Ant Plant Macaranga hullettii (Euphorbiaceae) In Southeast Asia. American Journal of Botany. 89(1): 50-59.

Navarro, L., Ayensa, G., Guitian, P. (2007) Adaptation of floral traits and mating system to pollinator unpredictibility: the case of Disterigma stereophyllum (Ericaceae) in southwestern Colombia. Pl. Syst. Evol. 266: 165-174.

Norton, S.A. (1984)Thrips pollination in the lowland forest of New Zealand. New Zealand Journal of Ecology 7: 157-164.

Obute, G.C. (2010) Pollination: A threatened vital biodiversity service to humans and the environment. International Journal of Biodiversity and Conservation. 2(1): 001-013.

Pallant, J. (2005) SPSS Survival Manual. A Step By Step Guide To Data Analysis Using SPSS For Windows (Version 12). NSW Australia. Allen \& Unwin.
Pramono, A.A. (2013) Fenologi Surian (Toona sinensis) di Beberapa Lokasi Hutan Rakyat di Jawa Barat. Di dalam: Prosiding Seminar Nasional Agroforestri 2013, tanggal 21 Mei 2013 di Malang. Ciamis. Kerjasama Balai Penelitian Teknologi Agroforestry, Fakultas Pertanian Universitas Brawijaya, World Agroforestry Centre (ICRAF), dan Masyarakat Agroforestri Indonesia.p 723-729.

Proches, S., Johnson, S.D. (2009) Beetle pollination of the fruit-scented cones of the South African cycad Stangeria eriopus. American Journal of Botany. 96(9): 1722-1730.

Reddi, E.U.B. (1989) Thrips-Pollination in Sapodilla (Manilkara zapota). Proc. Indian. natn. Proceedings of the National Academy of Sciences B55. 5\&6: 407-410.

Terry, I.L. (2001) Thrips: the primeval pollinators? Di dalam: Marullo R, Mound L, editor.Thrips and Tospoviruses: Proceedings of the 7th International Symposium on Thysanoptera. Reggio Calabria, Italy, from the $2^{\text {nd }}$ to the $7^{\text {th }}$ of July 200. Canberra : Australian National Insect Collection CSIRO. hlm 157-162. 